\title{
Discussion on Project Teaching Mode Applied in Chemical Engineering Teaching of Secondary Technical Vocational School
}

\author{
Xueping Zhou \\ Jiangde Industrial Technology School, Hangzhou, Zhejiang, 311612
}

Keywords: Project teaching, Secondary vocational chemical engineering, Construction.

\begin{abstract}
For the past few years, China's education has realized the great substantial leap and secondary vocational education level has also been greatly improved. However, the secondary vocational education is challenged by expanding enrollment scale of all institutions and the changing demands for talents as required by society. In the context, the conventional teaching modes fail to catch up with the current teaching. As one teaching pattern which is highly practical, the project teaching method plays a giant role in transferring the theoretical knowledge of the students into practical ability. On this basis, the author makes the brief analysis on the practice teaching system of existing chemical engineering teaching. And the construction idea of project-based teaching mode in the chemical engineering teaching of Secondary Technical Vocational School is also proposed in the paper, in the hope of providing references and suggestions on the reform of secondary vocational teaching.
\end{abstract}

\section{Introduction}

Secondary vocational education serves to cultivate the technical talent with the strong skills, in which students are guided to expertly master the basic professional knowledge and to combine the professional basic technology with the technical operation. Therefore, the students are expected to be adequate for the job of certain technical operation after receiving the secondary vocational education and to master the basic operation technique for other works. So, the secondary vocational education is perceived as an educational stage to attach great importance to the cultivation of students' practical ability. From the secondary vocational teaching at present, however, the traditional teaching method fails to both stimulate the interest of the students and improve their ability in the practice. For the sake of training the professional and technical talents required by the society in the future and being advantageous in the future fierce competition for talents, the outdated teaching method shall be reformed and the project-based teaching pattern shall be adopted to enhance their practical ability. In this way, it is to accelerate the secondary vocational education to comply with the times and make progresses.

\section{Analysis of Chemical Engineering Teaching of Secondary Vocational Education}

Accompanying with the development of China's education, all parts of education have been vastly progressing. In recent years when the enrollment of secondary vocational school has been expanding, the discrepancies have been shown in some students' understanding of the basic knowledge on account of the low access to the secondary vocational schools. Those weak in basic knowledge fail to keep up with the teachers during the process of teaching, while those stronger might think the teaching too slow. So the different basic knowledge levels among the students have impeded the smooth development of the chemical engineering teaching of secondary vocational education.

For many students, they come to the secondary vocational schools for parents' order, the diploma of secondary vocational chemical engineering and even dawdling and getting rid of parents. 
Only fewer students think it the necessary stage for future work. Under the circumstance, their unclear learning objectives and disinterest in studying make it less likely to improve the efficiency of learning.

Chemical engineering highly emphasizes the students' practical ability. However, fewer opportunities to practice provided by the secondary vocational schools lead to the students' failure in practicing in chemical engineering, and the chemical operation technology of their own cannot be further improved so that the professional knowledge and skills are limited to the theory. When the students get started, they are likely to spend more time on adaptation, and it is much likely to train the talents who are less advantaged.

\section{The Introduction of Project Teaching in Secondary Vocational Chemical Engineering Teaching}

In the project teaching method, the students are to complete a task independently under the guidance of teachers, and that applied in the chemical engineering teaching in secondary vocational schools is to ask the students to finish the project task involved in the chemical engineering alone. In that way, the students' knowledge about the chemical engineering can be strengthened and it also works to improve their chemical technology, operation skills and practice ability. It shall be noted that the projects in the project-based teaching method are required to what is actually needed in the students' positions related to chemical engineering in the future. As required in the teaching program, the problems that the students may meet in the specific operation techniques in the future posts shall be integrated in the project. To this end, the teachers who design the project are required to possess the practical experiences in chemical engineering and to teach them the knowledge about operation methods and problem solving accurately, so as to effectively improve their chemical engineering technology, operation skills and practical ability.

\section{The Construction Idea of Project-based Model Practice Teaching}

The project consists of inorganic, organic and analytical chemistry, the basic chemistry experiment and comprehensive experiment of some specialized courses. Determined by the features of chemical engineering, the chemical engineering courses are not likely to correspond with all chemical production projects, such as the basic chemical reaction and the basic experimental operation which exactly shall be mastered by the qualified chemical operators. Therefore, when designing the project course for the chemical engineering, it will be perceived as the project tasks of the curriculum if there are corresponding complete product production processes as project task. If not, we might as well design a full basic experiment as a project task for the designing. For the students involved in the majors for the first time, the experimental projects or small projects will actually benefit their study and help them in the transformation from knowledge accumulation to ability generation. In the designing of the chemical experiment project, it shall consider how to realize the mutual intersection and penetration between the courses in terms of the contents, and set the increasingly updated comprehensive designing experiments, so that the students' discipline-based comprehensive ability can be cultivated.

In the project, chemical drawing and CAD training, chemical equipment operation and maintenance training, chemical unit operation training, chemical process operation training and computer simulation operation training are covered. Almost all of them are involved in the chemical production process, so the project plays a crucial role in the whole practice teaching system. The chemical training projects are observably marked by independence, strong productivity and modularity, and most complete project work processes are easy to carry out project-based teaching. There are more researches on project-based teaching in the major of chemistry engineering in Secondary Vocational Schools. However, the difficulties in training equipment and site construction obstruct the training project teaching.

The project mainly includes the professional qualification textual research projects, like productive training, substituted post exercitation, junior and intermediate chemical analyst, 
chemical operator and general engineer of chemical engineering. The training goal of chemical engineering specialty in secondary vocational school determines that the practice teaching system of chemical specialty shall focus on the subject of students' professional ability and the combination between the specialized courses with professional abilities. For the sake of effectively strengthening the student's practical ability and shortening the actual distance between teaching and vocational posts, the students shall receive the productive training and internship in the enterprises matching with the specialty to exercise practical ability, develop the operational skills, accumulate experience in the practical work and prepare for employment. In order to more define the training target of chemical engineering specialty, the corresponding national vocational qualification shall be perceived as the training direction based on the major features and the professional core competence of local chemical engineering industry. In the specialty, it is suggested to cultivate towards the direction of vocational qualifications like junior and intermediate chemical analyst, chemical operator and general engineer of chemical engineering.

\section{The Construction Strategy of Project Teaching System}

For the vast majority of secondary vocational schools, chemical engineering is the major with fewer students, fewer teachers and fewer teaching facilities. And both faculties and fund investment are the stumbling block in the implementation of project teaching in chemical engineering compared to the backbone specialty in the school. Under the circumstance, it will be great challenges for secondary vocational chemical engineering to construct a practical teaching system in line with the project course of its own. In the view of the author, the following methods can be adopted to build a practical teaching system matching the secondary vocational chemical engineering.

The existing experimental training equipment and places for the secondary vocational chemical engineering is designed according to the original subject-type teaching method and they shall be adjusted and designed systematically to conform to the requirements of project-based teaching. In the basic framework of the new practice teaching system, the original laboratory shall be optimized and aggregated, to break the mode independently set in the past experiment and to build the new experimental teaching system through the experiment with the combination of theory and practice and the training design model. In terms of the specific operation, the distinction between disciplines and functional laboratory shall be diluted, the laboratory shall be set separately in accordance with the requirements of project teaching, and the professional teaching experimental center shall be established. Based on the overall training of talents, All the laboratories and specialized teaching experimental centers shall build the project courses experimental teaching system which is scientific, systematic, hierarchical, multi-module and mutually connected and to mainly develop the ability, so as to create a good school experiment environment for students' training of basic practical skills.

In spite of the limited finance and resources in the secondary vocational schools, the manpower and financial resources needed for construction can be vastly enriched by uniting the schools and striving for the government investment, so that the target of constructing the practice teaching system can be realized. In this regard, we are greatly inspired by the construction of many large and medium-sized university cities and vocational education parks. The secondary vocational schools in the same region and the city can be united to construct and share the experimental training base by imitating the construction pattern of shared resources in both university towns and vocational education parks, and strive for the government finance. The secondary vocational schools shall work together with the chemical industry park based on in-depth research and make the effective construction plan of public training base. Moreover, they shall jointly call for the government investment in the construction. If it works, the construction of shared training bases for chemical engineering specialty can be realized.

During the production of chemical products, it is defined by systematicness, strong exclusiveness, high production relevancy, high hazards, high requirements for transportation and strict environmental protections, which determines that it is difficult to build a real product training device on campus or only few training devices can be set up, so that the teaching needs of the 
project curriculum system cannot be satisfied at all. Furthermore, the chemical engineering specialty is committed to cultivating the first-line technical workers for chemical production and it shall be supported by the enterprises to train the front-line technical personnel suitable for modern enterprises. In the construction of practical teaching system for project course, it is a highly vital part to work together with the enterprises and adopt the actual enterprises' production places as the practice and training base for students' operation skills. The school-enterprise cooperation and the training base combined with learning and working can address not merely the problems related to students' practical operations in the project teaching process but also the difficulties in their productive practice teaching like replacement internship after graduation. What's more, the enterprises can be provided with more convenient ways to directly investigate and recruit the graduates majoring in chemical engineering.

\section{Conclusion}

In the new context of teaching, it is extremely urgent to innovate and reform the teaching method of secondary vocational chemical engineering. And the project-based teaching pattern with the combination of theory and practice works to improve the chemical operation skills and practical ability of students in secondary vocational school. Therefore, both schools and teachers shall understand how the project teaching is important and master the corresponding application methods of project teaching to effectively improve the students' practical ability, cultivate the chemical professional talents needed in the future and accelerate the development and progress of secondary vocational education.

\section{References}

[1] Ren Juan. Application of Project Teaching Method in Secondary Vocational School Chemical Engineering Teaching [C]. World’s Star Innovation Education Forum, 2016.

[2] Sheng Fengjun. Construction of Project-based Secondary Vocational Chemical Engineering Curriculum [D]. Awarded Paper of The Fourth Creative Forum, 2010.

[3] Sheng Fengjun. Construction of Practice Teaching System of Secondary Vocational Chemical Engineering Project Curriculum [J]. Shandong Chemical Engineering, 2015 (23): 123 - 125.

[4] Jiang Jing. Project Teaching Method -- An Innovative Model of Secondary Vocational Chemical Engineering Teaching [J]. New Curriculum•Middle, 2014 (04): 90 - 93.

[5] Wu Yingying. Research on Project Teaching Method in Secondary Vocational Chemical Engineering Specialized Chemistry Course Teaching [J]. Education: Digest Edition, 2016 (01):254254. 